Hot topics in necrotising skin and soft tissue infections

Kordo Saeed, Silvano Esposito, Ian Gould, Tiziana Ascione , Matteo Bassetti, Eric Bonnet, Emilio Bouza, Monica Chan, Joshua S Davis, Giuseppe De Simone, Matthew Dryden , Thomas Gottlieb, Karolin Hijazi , David C Lye ,

Pasquale Pagliano, Christina Petridou, Elda Righi, John Segreti , Serhet Unal , Ata Nevzat Yalcin

PII: S0924-8579(18)30050-5

DOI: 10.1016/j.ijantimicag.2018.02.012

Reference: ANTAGE 5381

To appear in: International Journal of Antimicrobial Agents

Received date: $\quad 20$ November 2017

Revised date: $\quad 22$ January 2018

Accepted date: $\quad 17$ February 2018

Please cite this article as: Kordo Saeed, Silvano Esposito, lan Gould, Tiziana Ascione, Matteo Bassetti, Eric Bonnet, Emilio Bouza, Monica Chan, Joshua S Davis, Giuseppe De Simone, Matthew Dryden, Thomas Gottlieb, Karolin Hijazi , David C Lye , Pasquale Pagliano, Christina Petridou, Elda Righi, John Segreti, Serhet Unal , Ata Nevzat Yalcin, Hot topics in necrotising skin and soft tissue infections, International Journal of Antimicrobial Agents (2018), doi: 10.1016/j.ijantimicag.2018.02.012

This is a PDF file of an unedited manuscript that has been accepted for publication. As a service to our customers we are providing this early version of the manuscript. The manuscript will undergo copyediting, typesetting, and review of the resulting proof before it is published in its final form. Please note that during the production process errors may be discovered which could affect the content, and all legal disclaimers that apply to the journal pertain. 


\section{Hot topics in necrotising skin and soft tissue}

\section{infections}

Kordo Saeed ${ }^{1,2}$, Silvano Esposito ${ }^{3}$, lan Gould ${ }^{4}$, Tiziana Ascione ${ }^{5}$, Matteo Bassetti ${ }^{6}$, Eric Bonnet ${ }^{7}$, Emilio Bouza $^{8}$, Monica Chan ${ }^{9}$, Joshua S Davis ${ }^{10}$, Giuseppe De Simone ${ }^{3}$, Matthew Dryden ${ }^{1,2,11}$, Thomas Gottlieb ${ }^{12}$, Karolin Hijazi $^{13}$, David C Lye ${ }^{9,14,15}$, Pasquale Pagliano ${ }^{5}$, Christina Petridou ${ }^{11}$, Elda Righi ${ }^{6}$, John Segreti ${ }^{16}$, Serhet Unal ${ }^{17}$, Ata Nevzat Yalcin ${ }^{18}$ on behalf of the International Society of Antimicrobial Chemotherapy

1. Department of Microbiology, Hampshire Hospitals NHS Foundation Trust, Basingstoke and Winchereter, UK

2. University of Southampton, School of medicine, Southampton, UK

3. Department of Infectious Diseases, University of Salerno, Salerno, Italy

4. Medical Microbiology, Aberdeen Royal Infirmary, Foresterhill, Aberdeen, UK

5. AORN dei Colli Dept of Infectious Diseases, Naples, Italy

6. Infectious Diseases Clinic, Department of Medicine University of Udine and Azienda Sanitaria Universitaria Integrata, Udine, Italy

7. Department of Infectious Diseases, Hôpital Joseph Ducuing, Toulouse, France

8. Clinical Microbiology and Infectious Diseases Department, Hospital General Universitario Gregorio Marañón, Madrid, Spain

9. Department of Infectious Diseases, Tan Tock Seng Hospital, Singapore.

10. Department of Infectious Diseases, John Hunter Hospital, Newcastle, NSW, Australia ; and Global and Tropical Health Division, Menzies School of Health Research, Darwin, NT, Australia

11. Public Health England, Porton Down, UK

12. Department of Microbiology \& Infectious Diseases, Concord Hospital, Concord, NSW, Australia

13. Institute of Dentistry, School of Medicine, Medical Sciences \& Nutrition, University of Aberdeen. 
14. Institute of Infectious Diseases and Epidemiology, Communicable Diseases Centre, Tan Tock Seng Hospital, Singapore

15. Lee Kong Chian School of Medicine, Nanyang Technological University, Singapore

16. Department of Infectious Diseases, Rush University Medical Center, Chicago, IL, USA

17. Department of Infectious Diseases, Faculty of Medicine, Hacettepe University, Ankara, Turkey

18. Department of Infectious Diseases and Clinical Microbiology, Faculty of Medicine, Akdeniz University, Antalya, Turkey

\section{Keywords:}

Skin and soft tissue infections

Necrotising fasciitis

Panton-Valentine leukocidin

Immunocompromised

Intravenous immunoglobulin G

Pyomyositis

Gas gangrene

\section{Introduction}

Skin and soft tissue infections (SSTI) are amongst the most common infections encountered in clinical practice. Although the majority of infections do not result in skin or tissue necrosis, those that do are associated with a high mortality rate. In addition, due to the surreptitious presentation of the disease clinical recognition is often delayed resulting in rapid and overwhelming morbidity.

Necrotising skin and soft tissue infections (NSSTI) are a spectrum of conditions and their presentation can vary depending on host and microbial factors. NSSTI can spread in the superficial skin layers causing a necrotising cellulitis or within deeper skin layers along the fascial planes causing necrotising 
fasciitis (NF) and can occasionally invade muscles causing a necrotising pyomyositis. A variety of microorganisms may be responsible and common pathogens under certain conditions and in certain hosts may become aggressive and invasive resulting in skin death despite adequate treatment.

A number of 'hot topics' on NSSTI were selected and reviewed by members of the Skin, Soft Tissue and Bone Infections Working Group of the International Society of Antimicrobial Chemotherapy (ISAC). This group includes international scientists, microbiology and infectious diseases clinicians and academics, aiming to advance the education and the science of infection management. The following represents an in-depth review of the current literature providing a summary of the various NSSTIs and expert opinions and insights from the authors' own experience, highlighting areas for future study and research.

\section{Necrotising fasciitis: an overview}

Necrotising fasciitis (NF) is a severe, uncommon, potentially life-threatening infection if adequate debridement is not administered promptly [1]. Higher rates of disease are seen in men, and middleaged and elderly patients, although all age groups can be affected. Rates of 0.4/ 100,000 people per year in the USA and 1/100,000 in other countries have been reported however this may underestimate the true incidence of the disease.

Conditions associated with NF include diabetes mellitus, renal insufficiency, arterial occlusive disease, intravenous drug abuse, body mass index $>30 \mathrm{~kg} / \mathrm{m}^{2}$, age $>65$ years, liver disease, immunosuppression, recent surgery, and traumatic wounds or incision of the skin including minor lesions such as insect bites and injections sites [2-4]. NF has been classified into four types depending on microbiological findings: type I is of polymicrobial aetiology, including aerobic and anaerobic organisms; type II is caused by group A streptococci (GAS), either alone or in association with staphylococci; type III is represented by monomicrobial infections attributable to Clostridium species or Gram-negative bacteria; type IV is of fungal aetiology [1,5]. However, failure to identify an organism should never override the clinical diagnosis of NF.

Early diagnosis of NF is crucial, but can be challenging (Figure 1). The triad of swelling, erythema, and disproportionately severe pain should raise the suspicion of NF and the presence of blisters, bullae 
and skin crepitus is strongly suggestive. The Laboratory Risk Indicator for NF (LRINEC) is a scoring system encompassing six routinely performed laboratory tests used in conjunction with clinical signs, and has been used to distinguish early NF from the other severe SSTI. The laboratory tests include Creactive protein (CRP), mg/L ( $<150$ scores $0,>150$ scores 4$)$, total white cell count (WBC), cells $/ \mathrm{mm}(<15$ scores $0,>25$ scores 2$)$, haemoglobin, $(\mathrm{Hb}) \mathrm{g} / \mathrm{dL}(>13.5$ scores $0,<11$ scores 2), sodium, $\mathrm{mmol} / \mathrm{L}(\geq 135$ scores $0,<135$ scores 2$)$, creatinine, $\mathrm{mg} / \mathrm{dL}(\leq 1.6$ scores $0,>1.6$ scores 2) and glucose, $\mathrm{mg} / \mathrm{dL}(\leq 180$ scores $0,>180$ scores 1$)$ ] [6-9]. In one study the cut-off point of LRINEC scoring for predicting septic shock was 5 points (sensitivity $82 \%$ and specificity $38 \%$ ) whereas the cut-off point for predicting mortality was 8 points (sensitivity $81 \%$ and specificity $36 \%$ ). [9]. However, the usefulness of this score is still debated $[6,10]$ and although it may have a place in potentially including NF in a patient's clinical diagnosis, it should not be used to exclude it. Although imaging can provide useful information, it lacks specificity and should not delay prompt surgical management when NF is suspected. The gold standard for diagnosis of NF remains surgical exploration $[1,5,11,12]$. Early radical surgical debridement with removal of all necrotic and infected tissues is imperative in the treatment of NF and amputation of the affected limb may be necessary to achieve source control. Delayed first debridement is often associated with poor outcomes, while operating early tends to result in shorter hospital and Intensive Care Unit (ICU) lengths of stay [13, 14]. Empiric treatment with broad-spectrum antibiotics, guided by local epidemiology and resistance patterns, should be administrated early (Table 1), followed by targeted therapy if a pathogen is identified. The duration of optimum treatment is not defined, but should be continued until debridement is optimised and no further surgery is needed and there has been a clinical improvement. The role of intravenous immunoglobulin G (IVIG) therapy is discussed below. There is still no clear evidence to support the role of hyperbaric oxygen (HBO) as an adjunctive treatment in NF management but it may contribute to decreasing mortality and limiting the extent of debridement necessary [15]. Vacuum-assisted closure (VAC) devices allow the continuous cleansing of the wound and are widely used to improve and accelerate wound healing $[1,5,11,12,16]$. Reactive Oxygen gels have been used topically to suppress the bacterial load in tissue and support healing and may be used as an adjuvant to debridement and antibiotic therapy [17]. 


\section{Group A Streptococcal necrotising fasciitis}

GAS is one of the most common organisms isolated in cases of NF [18]. Certain strains are more pathogenic with the emm 1 strain being the major lineage associated with invasive disease in Europe and the USA. Sequencing of an emml strain causing genital tract soft tissue necrosis, haemorrhagic pneumonia and streptococcal toxic shock has confirmed that spontaneous mutations may make strains of GAS become super-pathogens [19]. In one outbreak of GAS a mutation in the sic allele was associated with the outbreak isolates but was never identified again in isolates of GAS from the same region, suggesting that super-pathogens of this sort cause catastrophic infection in small numbers of patients, but do not possess the characteristics to persist in the host population [19]. Emm1 GAS is equipped with a range of virulence factors that allow it to cause a wide spectrum of disease [20], from asymptomatic colonisation, through to tonsillitis, cellulitis, NF, haemorrhagic pneumonia and bacteraemic toxic shock as well as the ability to cause outbreaks [21]. Despite the above, a wide variety of emm types of GAS can cause NF, and emm-1 may cause non-invasive infection, hence the importance of emm type remains unclear.

The diagnosis depends on clinical suspicion [22] (Figure 1). The presentation of GAS NF is illustrated by the case of a 49-year old woman (Figure $2 \mathrm{a}$ and $2 \mathrm{~b}$ ). Early surgical exploration of the soft tissues has little morbidity and may be the only means to reach a definitive diagnosis and expedite treatment. The earlier the first exploration and subsequent debridement, the less extensive the resection and postoperative morbidity is likely to be [13, 14].

\section{Gram negative bacterial necrotising fasciitis}

Although Gram positive organisms are more typically associated with NSSTI, a variety of Gram negative organisms may also be responsible depending on local epidemiological and host factors. In a retrospective study of 323 consecutive patients with NF in Taiwan, monomicrobial infections were detected in 187 cases, 125 by tissue culture and 61 by blood culture; Staphylococcus aureus was identified in $33.7 \%$ of cases, GAS in $9.6 \%$, Vibrio vulnificus in $21.9 \%$, Aeromonas species in $9.1 \%$ and Klebsiella pneumoniae in 9.0\% [23]. Another Taiwanese study identified 42 patients with 
cirrhosis and NF, among which monomicrobial infections were detected in 41 patients and were mainly caused by Gram negative bacteria (76\%) including Vibrio species (36\%), Klebsiella species (21\%), and Aeromonas species (14\%). Patients with NF due to Gram negative bacteria were more likely to present with septic shock, but had similar in-hospital mortality compared with Gram positive NF [24].

A retrospective case series of 67 patients with $V$. vulnificus NF from Taiwan showed male predominance $(\mathrm{n}=52)$, cirrhosis in 23 patients, chronic renal impairment in 17, upper limbs affected in 50 , shock in 8 , bacteraemia in 38 and death in 8 . Repeated debridement of 4 or more times was needed in 39 cases and amputation in 3 [25]. In another retrospective study of 100 patients with $V$. vulnificus, delayed presentation of at least 3 days from disease onset was found to be an independent predictor of mortality [26]. Another retrospective study comparing 60 patients with V. yulnificus and 55 with $S$. aureus NF found leukopenia, thrombocytopenia, liver disorders, seawater and seafood exposure, ICU admission and a temperature of $38.5^{\circ} \mathrm{C}$ or above to be significantly more common in V. vulnificus, while diabetes mellitus, trauma, surgical wound infection and ulcers to be significantly more common in S. aureus NF [27]. V. vulnificus should be considered in any patient with known iron overload presenting with NF and empiric therapy should provide coverage for this organism.

In terms of diagnosis, a retrospective study of 70 patients with $V$. vulnificus with 18 deaths showed similar mean LRINEC scores between survivors and those who died, and only 8 had an LRINEC score of 6 or more [28]. However, LRINEC scores of 2 or more was shown to have a sensitivity of $71 \%$, specificity of $83 \%$ and negative predictive value of $85 \%$ in a retrospective study of 125 patients with V. vulnificus soft tissue infections of which 72 had NF [7].

A study of 89 patients with $V$. vulnificus NF showed a fluoroquinolone with or without minocycline, and third generation cephalosporins with minocycline were associated with significantly lower case fatality rates (14\%) compared with third generation cephalosporins alone (61\%) [29]. Surgical debridement within 12 hours of hospital presentation was shown to be associated with lower mortality compared with debridement within 12 to 24 hours or over 24 hours, adjusted for age, duration between disease onset and hospital presentation and illness severity, in a retrospective study of 121 patients with V. vulnificus NF of which 35 died [30]. The only study outside of Taiwan on V. vulnificus NF 
with septic shock was undertaken in China and showed less bleeding, lower intraoperative fluid and maximum dose of inotropic requirements, and lower mortality in 19 patients who received initial incision and drainage under regional anaesthesia followed by debridement over 24 hours later compared with 15 who received immediate surgical debridement, with similar baseline characteristics and illness severity [31].

Table 2 [32-37] summarises salient clinical data from the largest reported case series and literature reviews on other Gram negative bacterial NF. The largest cases series was reported for Pseudomonas species ( $\mathrm{n}=37)$, followed by K. pneumoniae $(\mathrm{n}=17)$ and Aeromonas species $(\mathrm{n}=13)$. Notably, Pseudomonas species NF occurred in younger patients (14/37 less than 10 years old) with neutropenia (11/37) and frequently involved the perineum (20/37). Likewise Salmonella species NF affected younger patients with only $1 / 6$ above 40 years old. Male predominance was observed in most except Pseudomonas species (15/37) and Salmonella species (2/6) NF. Diabetes mellitus was the main predisposing condition in K. pneumoniae (12/17), and corticosteroid use was reported in 4/6 with Salmonella species NF. Cancers were found in patients with Aeromonas species (5/13), Pseudomonas species (20/37) and E. coli (3/7) NF. Surgery was performed in the majority of patients in these series except Pseudomonas species (16/37) and E. coli $(2 / 7)$ NF. Mortality was particularly high $(>50 \%)$ in Aeromonas species (9/13) and E. coli (7/7) NF.

\section{PVL-positive Staphylococcus aureus related necrotising infections}

Panton-Valentine leukocidin (PVL) is a bicomponent, poreforming cytotoxin that causes leukocyte destruction and tissue necrosis produced by both methicillin sensitive and methicillin resistant $S$. aureus (MRSA). Risk factors for PVL related necrotising infections are; compromised skin integrity, skin-to-skin contact, including contact sports e.g. wrestling, sharing of contaminated towels and sheets and living in crowded accommodation [38]. Necrosis can be focal or more extensive including Fournier's gangrene, and secondary abscesses are common. Necrosis, abscesses and tissue destruction are suggested by local and general inflammatory symptoms [38]. Robust epidemiological evidence in the early 2000s had shown a strong association between S. aureus carrying the PVL gene and lethal necrotising pneumonia [39]. However, other studies have questioned the role of PVL as a consistent 
predictor of poorer clinical outcomes [40]. Experimental evidence demonstrating a causal association between PVL and necrotising infections is also conflicting particularly in murine models of infection [41]. It has been demonstrated in both correlation studies and experimental studies that in the absence of PVL other virulence factors can induce the necrotising phenotype of community-acquired (CA)MRSA, for example alpha-haemolysin, phenol-soluble modulin peptides and the arginine catabolic mobile element.

Early aggressive surgical debridement is recommended for patients with severe infections associated with signs of systemic toxicity where NF is suspected [42]. Currently inhibitors of toxin production such as clindamycin, linezolid or rifampicin are recommended for inclusion in antimicrobial treatment of necrotising infections related to $p v l$ positive $S$. aureus. A recent study indicated that treatment with tedizolid or linezolid alone yields higher survival rates than vancomycin in a rabbit model of necrotising pneumonia while the effect on bacterial counts in the lungs was comparable to vancomycin [43]. Combinations of vancomycin with clindamycin or rifampicin and linezolid or clindamycin with rifampicin have demonstrated clinical success and are discussed in a position statement from the ISAC [44]. A recent RCT of adjunctive clindamycin in non-necrotising cellulitis of the lower limb found no benefit, and an excess of diarrhoea in the clindamycin arm. However, lower doses of clindamycin were used, and prior usage for coamoxiclav did not account for this side effect [45]. A current Australian trial is evaluating the role of adjunctive clindamycin in children and adults with severe $S$. aureus infections, including pyomyositis and pneumonia (ACTR number to follow), but specific trials are needed in patients with NSSTI.

\section{Fungal necrotising skin and soft tissue infections}

Fungal NF is rare and most descriptions are limited to case reports. In healthy individuals fungal NF can follow soil exposure, motor-vehicle related trauma or burns [46] and can occasionally arise from an iatrogenic source after injections or contaminated surgical dressings. In immunocompromised patients infection often results from an extrinsic source and progression from a painless papule to 
necrotising infection may occur surreptitiously or as a fulminant process. Necrosis has been documented in up to $60 \%$ of these cases [47].

Fungal NF is usually due to infection by moulds including Aspergillus species, or more typically by zygomycete fungi, in particular Apophysomyces species has been primarily associated with infection in previously healthy patients following severe trauma potentially contaminated with soil. Jain et al reported 18 cases of zygomycotic NF from a single institute in India. Identification was by tissue biopsy and fungal culture [48]. Similarly, after a tornado in Missouri in 2011, a cluster of 13 patients with severe NSSTI were infected with a new species of Apophysomyces (Apophysomyces trapeziformis). The mortality rate was high (38\%) despite surgical debridement and antifungal therapy including liposomal amphotericin, azoles and echinocandins[49].

In immunocompromised patients skin infection may also occur secondary to disseminated infection, as typically seen with Fusarium species or Scedosporium prolificans. These cases are however more likely to present with ecthyma gangrenosum-like features than with NF, whereas Candida species and Cryptococcus neoformans tend to cause local nodular infection or cellulitis. Although primary cutaneous cryptococcosis has been described, disseminated cryptococcal disease especially to the central nervous system should be excluded. In a review of 12 patients with $C$. neoformans NF, the majority were immunosuppressed including 6 post-transplant patients. Despite combination treatment with surgical debridement and antifungal therapy with amphotericin B and 5-flucytosine induction therapy, overall mortality was $41.6 \%$ [50].

Cases of fungal NF of the head and neck due to Zygomycetes, in particular Apophysomyces species, have been reported in patients with decompensated diabetes, and results are often fatal [51]. A case series from Northern India identified seven cases (six due to A. variabilis and one due to A. elegans) possibly linked to infections following intramuscular injections [52]. 
Moulds can cross tissue planes and are angio-invasive, causing thrombosis, secondary infarction and local or extensive necrotic infection. Infections due to zygomycete fungi (cutaneous mucormycosis) follow a more rapid course from localised infection or an eschar to life-threatening gangrene [53-55]. Dissemination can also occur. Diagnosis can be delayed due to difficulties in obtaining a microbiological identification, for example Mucor species are fastidious if specimens are poorly handled and diagnosis may depend on adequate histopathology and the detection of irregular aseptate hyphae. Treatment requires early and repeated surgical debridement combined with medical therapy including a broad spectrum antifungal such as liposomal amphotericin B (or isavuconazole if zygomycetes are suspected). Compared with Aspergillus species infections medical treatment options in Mucor species infections are limited and the clinical response is less predictable [56].

\section{Necrotising skin infections in the immunocompromised}

Immunosuppressed patients appear to be more susceptible to NSSTI, primarily related to the increased risk of translocation of bowel organisms, and the degree and duration of the neutropenia as well as frequent presence of mucositis related to chemotherapeutic agents or graft versus host disease [57]. In the immunocompromised host, physical examination and clinical findings may be subtle hence the diagnosis can be even more challenging and laboratory findings can be nonspecific. Often the diagnosis is only considered late in the course of the disease when tissue necrosis is obvious and the patient is critically ill. Unsurprisingly, these patients tend to have poor prognosis and unfavourable outcomes.

In a retrospective study of $668 \mathrm{NF}$ cases using the National Surgical Quality Improvement Program registry, conditions associated with immunocompromised status such as malignancy and treatment with corticosteroids were reported in less than $10 \%$ of cases and were found to be associated with increased mortality. No data was reported in this study on the characteristics of NF presentation in immunocompromised patients [58]. 
In another retrospective study involving 201 patients from a single centre the authors tried to identify the characteristics of NF presentation in immunocompromised patients. Immunocompromised patients reported less purulent drainage, lower systolic blood pressure and were more frequently admitted to medical units( even after referrals to tertiary centers) and were less likely to undergo surgical debridement at the time of admission resulting in poorer outcomes. Laboratory findings highlighted an important difference in the white blood cell count, which was lower than in the general population. This should be considered when calculating the LRINEC score in the immunocompromised. Immunocompromised patients had 2 times higher mortality $(\sim 40 \%)$ than NF-related mortality in immunocompetent individuals. There was no difference in microbiological findings or antimicrobial therapy highlighted in immunocompromised patients [59].

Ecthyma gangrenosum, haemorrhagic pustules that evolve into necrotic ulcers, is a relatively uncommon condition, but is one of the commonest manifestations of necrotising skin infections in immunosuppressed patients [60]. At one time it was postulated that this condition was pathognomonic of Pseudomonas aeruginosa bacteraemia. It is now clear that a variety of bacteria as well as fungi including Candida spp, Fusarium and Aspergillus can also cause ecthyma gangrenosum. The pathophysiology is that the organisms invade the venules, resulting in secondary thrombosis of the arterioles, tissue oedema, and necrosis. Many patients with ecthyma gangrenosum have an associated bacteraemia. Blood cultures and skin biopsies are necessary for diagnosis. The differential diagnosis of ecthyma gangrenosum and NSSTI in immunosuppressed patients includes any process that can produce skin necrosisincluding acute graft versus host disease, drug-induced skin necrosis, calciphylaxis, septic emboli, diabetic microangiopathy, disseminated intravascular coagulation, vasculitis, and Sweet's syndrome [61]. Skin biopsies should be sent for tissue culture for bacteria, fungi, yeasts, and mycobacteria. In addition to urgent surgical debridement, treatment entails empiric coverage for P. aeruginosa, enteric Gram negative bacteria, staphylococci and fungi until culture results are available.

Diagnosis of NF and/or myonecrosis should be considered in any immunocompromised patient with fever, tachycardia, and localized pain out of proportion to the physical findings. The spectrum of potential pathogens is expanded to include rare invasive moulds, fungi, mycobacteria and even 
parasites in certain geographical regions. Existing anti-infective prophylaxis may select for multidrug resistant organisms or azole resistant moulds and fungi. The need for multiple invasive procedures and devices increases the risk of environmental introduction. Where possible, immunosuppressive regimens should be tapered. Data on the optimal management of these patients remains limited and should be individualised.

\section{Necrotising infections in intravenous drug users:}

SSTIs are much more common in intravenous drug users (IVDUs) than the general population, reasons include that over half of IVDUs are colonised with S.aureus; they sustain repeated non-sterile injections; and may have relative immunodeficiency due to poor nutrition and/or HIV infection. Observational studies among IVDU populations report SSTIs occurring in 30-60\% at any time and at least yearly in 10\%-34\% of IVDUs [62-64]. In a case-controlled study including 151 IVDUs, risk factors for skin and soft-tissue abscesses (SSTA) included direct injection into skin or muscle [65]. Other risks include non-vein injection ("skin-popping" - injecting subcutaneously and "musclepopping" - intramuscular injection) and injecting into the neck or groin 63]. In addition, the particular drug being injected influences the risk of infection, with "speed-ball”, "black tar heroin" and prescribed opiates all being associated with a higher risk of infection.

Although most invasive infections in IVDU are due to S. aureus including CA-MRSA [66], the range of causative organisms is much broader than in the general population. In addition to Gram positive cocci, SSTI in IVDUs due to Candida species, Bacillus anthracis, anaerobes (including Clostridium species) and environmental bacteria such as Pseudomonas species are well described. Hence it is imperative for diagnostic samples to be taken, ideally prior to empiric antibiotic treatment, including pus from abscesses or furuncles, and blood cultures in those with systemic symptoms.

The clinical presentation of SSTIs in IVDUs differs from that of the general population, with IVDUs more likely to have multiple abscesses, involvement of the upper limb and groin, and to require surgical drainage in the operating theatre. The most common SSTI in IVDUs are skin abscesses, usually at injection sites, most commonly in the cubital fossa, the groin and the neck. Cellulitis, NF and furunculosis also occur but are less common. Imaging is often needed to differentiate SSTA from 
other lesions (e.g., haematomas, phlegmon or vascular complications) and evaluate the extent of infection [66].

If the presence of an abscess is confirmed, complete incision and drainage should be performed. Uncomplicated SSTI such as cellulitis can be treated with antimicrobials active against Gram-positive bacteria (Table 1) However, SSTA are polymicrobial in up to $50 \%$ of cases and can include $B$. anthracis and anaerobes due to drug contamination or heat-resistant anaerobes [65 66, 67]. Furthermore, the presence of devitalised tissue at the injection site in heroin users represents an ideal anaerobic microenvironment for life threatening infections such as wound botulism, tetanus, and NF [65, 68-70]. Other complications of SSTI in IVDUs include pyomyositis, bacteraemia, and endocarditis as well as chronic cutaneous venous ulcers that are often debilitating and require a multidisciplinary approach involving vascular and plastic surgeons, and can potentially lead to osteomyelitis. Management plans should include management of comorbidities such as alcohol and drug dependence. Endocarditis needs to be excluded and the opportunity taken to offer counselling and to check patients for blood borne viruses.

\section{Paediatric necrotising SSTI}

NSSTI is an uncommon, but potentially devastating infection in childhood responsible for $1.12 / 10,000$ hospital discharges [71]. An association of NSSTI with several comorbid conditions including coagulopathy, diabetes mellitus, electrolyte disturbance, and obesity has been documented. Cases associated with yaricella are reported less frequently after varicella vaccination.

Microbiological investigation from non-haematogenous sites demonstrates that streptococci and staphylococci are reported with the highest frequency and that Gram-negative organisms are cultured in less than $10 \%$ of cases. Staphylococci are the main bacteria isolated from blood cultures. Polymicrobial infections exceed $10 \%$ and $P$. aeruginosa infections are reported in the immunocompromised. Children with NSSTI are frequently febrile and report local symptoms and pain, and severe cases present with tachycardia, hypotension and altered mental status. The legs and trunk are the sites affected most frequently. Cumulative rates of ICU admission approaches $20 \%$, but children aged 4 years or less report a rate of ICU admission exceeding $60 \%$ according to a 
retrospective study by Endorf et al. On the basis of this study surgery involving the skin or muscle was performed in the majority of cases however the need for a fasciotomy was less than $10 \%$. There was a link between surgery within 24 hours from admission and favourable outcomes [72].

Broad-spectrum antibiotics are frequently administered as empiric therapy, covering a range of pathogens including $P$. aeruginosa and MRSA in highly endemic areas. No class of antibiotic has been particularly associated with a favourable outcome. The mortality rate for NSSTI in children is estimated at $6 \%$. The main variables affecting the mortality rate are severe sepsis and mechanical ventilation. Amputations are reported in $4 \%$ or less of the cases investigated. Children experiencing NSSTI had to be discharged more frequently to a rehabilitation nursing facility than the overall population of hospitalised children [73].

\section{Pyomyositis}

Pyomyositis is an acute bacterial infection of skeletal muscle that often arises from haematogenous spread and results in localized abscess formation.Pyomyositis is more frequent in tropical areas, for example, in eastern Uganda, 400-900 cases of tropical myositis occur per year while approximately 676 cases have been reported in the US literature since 1971. The peak incidence of tropical pyomyositis is in children aged 2 to 5 and young adults aged 20 to 45 , while the majority of temperate pyomyositis cases occur in adults. Males appear to be more commonly affected than females. Its incidence has increased in temperate zones, particularly among IVDUs, immunosuppressed patients such as those with HIV, patients with underlying comorbidities such as diabetes mellitus and cirrhosis and patients with concurrent infections including toxocariasis and varicella. Traumatic injuries also increase the risk of pyomyositis since haematoma formation and increased muscle perfusion provide favourable bacterial growth conditions [74-78].

The microorganism most often responsible for pyomyositis is S. aureus, causing up to $90 \%$ of infections in tropical areas and $75 \%$ in temperate zones, followed by GAS. Less frequent agents include Streptococcus pneumoniae, Neisseria meningitidis and Gram negative bacilli. E. coli is an emerging agent of pyomyositis in patients with haematological malignancies. Rare cases of mycobacterial pyomyositis have also been reported. 
Typically, patients with pyomyositis present with fever and muscle pain, most often localised to a single muscle group affecting the lower limbs or psoas muscles, but any muscle group can be affected including pelvic and upper extremity muscles and multifocal infection has been observed in up to $20 \%$ of cases. Three clinical stages are commonly described (Table 3) [42, 76]

MRI is the most useful imaging modality for the diagnosis of pyomyositis, showing signs of muscle inflammation. CT scan and ultrasonography may be helpful $[42,79,80]$. Drainage may be guided by imaging and the culture of specimens is crucial for microbiological diagnosis and to obtain antibiotic susceptibility data. Blood cultures are positive in 10-35\% of cases. Leukocytosis, elevated ESR and CRP are common findings but there are no specific biological markers of pyomyositis. Mortality is reported in approximately $10 \%$ of patients.

\section{Gas gangrene}

Gas gangrene or clostridial myonecrosis is caused by an anaerobic, Gram-positive, spore-forming bacillus of the genus Clostridium and C.perfringens is the most common species. Other aerobic and anaerobic bacteria are also capable of forming gas and can cause non-clostridial gas gangrene. $C$. perfringens produces at least 20 exotoxins including lethal Alpha and Beta toxins which can have necrotising and haemolytic effects. The true incidence is not known. Clinical presentation depends on precipitating factors e.g. trauma or surgery or spontaneous gas gangrene in patients with occult malignancies.

Like other NF infections, sudden onset disproportionate pain is usually present and worsens as the underlying infection spreads with or without constitutional symptoms, hypotension and altered mental status. The pain is followed by localised swelling, discharge (non-odorous or a sweet odour) and progressive skin changes including a dark bluish discolouration with blisters and haemorrhagic bullae. Crepitus may not always be detected with palpation due to swelling and oedema. 
Patients' WBC may be normal; however their biochemical profile may show significant metabolic abnormalities frequently associated with tissue injuries with hypotension and toxic shock. Presence or absence of gas in soft tissue on X-ray, neither confirms nor excludes the diagnosis of gas gangrene. CT, MRI and ultrasound imaging can all be used, but may not exclude a diagnosis and may cause delay in management. Early surgical exploration, biopsy and extensive debridement can confirm the diagnosis and can be a determining factor for successful outcomes with adjuvant therapies including antimicrobials (Table 1) and IVIG. The addition of clindamycin, chloramphenicol, rifampin or tetracycline may be effective by inhibiting the synthesis of clostridial exotoxins [81]. The mortality rate is very high, varying from $25 \%$ to $100 \%$ in individuals with spontaneous gas gangrene and in cases where surgical debridement is delayed $[82,83]$.

\section{The role of Intravenous immunoglobulin (IVIG)}

IVIG is prepared from pooled immunoglobulin from a large number of human donors. The continuing increase in demand has led to concerns over availability and rising costs. It is generally well tolerated although anaphylactoid reactions can occur and there are ongoing fears about the risk of transmission of infections such as CJD [84].

With regards to its place as adjunctive therapy in the management of NSSTI, experimental studies have shown that IVIG results in the neutralisation of superantigens produced by GAS and S. aureus, immunomodulation of the inflammatory cascade and may assist bacterial opsonisation [85-88]. There are only a few large randomised controlled trials supporting the use of IVIG in NSSTI and publications are largely limited to numerous case reports, small comparative observational studies and retrospective reviews [89-91]. Its use was evaluated in a multicentre, randomised double-blind placebo-controlled study which was terminated prematurely due to slow patient recruitment. Results from 21 enrolled patients showed a significant decrease in the sepsis-related organ failure assessment score and, although statistical significance was not reached, a 3.6 times higher mortality rate was seen 
in the placebo group [92]. Furthermore an observational cohort study involving 21 patients given adjunctive IVIG therapy for streptococcal toxic shock syndrome and 32 control patients reported significantly reduced mortality rates in patients given IVIG compared with controls (67\% vs. $34 \%$ ) [93]. A Swedish comparative observational study involving 75 patients with streptococcal toxic shock syndrome where most patients had SSTI also revealed a significantly improved 28 day mortality rate in the patients who received IVIG (87\% vs. 50\%) [94]. These reports, together with those detailing the mechanistic action of IVIG, support the use of IVIG as an adjunctive treatment in severe NSSTI caused by GAS and S. aureus; however larger trials are needed to support its use given the shortage of IVIG and the associated cost. In contrast to these publications, a retrospective study involving a paediatric cohort showed no mortality benefit but higher associated costs in those patients given IVIG, again stressing the importance for further clinical trials to investigate this [95]. 


\section{Conclusions}

NSSTIs are the most severe form of SSTIs. The ICS working group felt it important to discuss these infections in this review because of two main factors. Firstly, these infections commonly afflict even previously healthy people in the community without warning, rapidly progressing to sepsis and death and those who survive may be left with devastating, life-changing disabilities. Secondly, clinicians may lack the experience to recognise NF early and although the majority of SSTIs do not result in rapid destruction of soft tissue and toxaemia, it is important for all health professionals to be aware of these infections and consider them when patients present with pain out of proportion to the clinical signs with systemic, flu like symptoms and feverishness with raised inflammatory markers. This manuscript highlights some of the challenges associated with clinical diagnosis, as well as areas for future study and research in the fields of antimicrobials and adjuvant therapy, emphasising the urgency of surgical referral and debridement in any suspected cases of NSSTI. As members of ISAC we would like to propose the formation of an International Registry for cases of NSSTI to learn more about diagnostic and therapeutic opportunities for these cases.

\section{Acknowledgements}

Thanks to Drs Sophie Carr, Deepasree Bangaru-Raju and Umed Nadir for allowing us to share their Hampshire Hospitals poster (figure 1) in this manuscript.

\section{Declarations \\ Funding: No funding}

Competing Interests: No conflicts of interest

Ethical Approval: Not required 


\section{References}

1. Esposito S, Bassetti M, Concia E, De Simone G, De Rosa FG, Grossi P, et al; Italian Society of Infectious and TropicalDiseases. Diagnosis and management of skin and soft-tissue infections (SSTI). A literature review and consensus statement: an update. J Chemother. 2017; 29: 197-214.

2. Misiakos EP, Bagias G, Papadopoulos I, Danias N, Patapis P, Machairas N, et al. Early Diagnosis and Surgical Treatment for Necrotizing Fasciitis: A Multicenter Study. Front Surg. 2017; 4:5. doi: $\underline{10.3389 / \text { fsurg. } 2017.00005}$

3. Chen KJ, Klingel M, McLeod S, Mindra S, Ng VK. Presentation and outcomes of necrotizing soft tissue infections. Int J Gen Med. 2017; 10: 215-220.

4. Dryden MS. Complicated skin and soft tissue infection. J Antimicrob Chemother 2010; 65 Suppl 3: iii35-44

5. Esposito S, Bassetti M, Borre' S, Bouza E, Dryden M, Fantoni M, et al; Italian Society of Infectious Tropical Diseases; International Society of Chemotherapy. Diagnosis and management of skin and soft-tissue infections (SSTI): a literature review and consensus statement on behalf of the Italian Society of Infectious Diseases and/nternational Society of Chemotherapy. J Chemother. 2011; 23: 251-262.

6. Wong CH, Khin LW, Heng KS, Low CO. The LRINEC (Laboratory Risk Indicator for Necrotizing Fasciitis) score: a tool for distinguishing necrotizing fasciitis from other soft tissue infections. Crit Care Med. 2004; 32: 1535-1541.

7. Chao WN, Tsai SJ, Tsai CF, Su CH, Chan KS, Lee YT, et al. The Laboratory Risk Indicator for Necrotizing Fasciitis score for discernment of necrotizing fasciitis originated from Vibrio vulnificus infections. J Trauma Acute Care Surg. 2012;73:1576-1582.

8. Thomas AJ, Meyer TK. Retrospective evaluation of laboratory-based diagnostic tools for cervical necrotizing fasciitis. Laryngoscope. 2012; 122: 2683-2687.

9. El-Menyar A, Asim M, Mudali I N, Mekkodathil A, Latifi R, Al-Thani H. The laboratory risk indicator for necrotizing fasciitis (LRINEC) scoring: the diagnostic and potential prognostic role. Scand J Trauma Resusc Emerg Med. 2017; 25: 28. doi: 10.1186/s13049-017-0359-z 
10. Neeki MM, Dong F, Au C, Toy J, Khoshab N, Lee C, et al. Evaluating the Laboratory Risk Indicator to Differentiate Cellulitis from Necrotizing Fasciitis in the Emergency Department. West J Emerg Med. 2017; 18: 684-689.

11. Sanchez-Porto A, Martin-Gomez M, Casanova-Roman M, Casas-Ciria J, Nacle B. Necrotizing soft-tissueinfections in a general hospital. InfezMed. 2010;18:191-192.

12. Esposito S, Bassetti M, Bonnet E, Bouza E, Chan M, De Simone G, et al;. Hot topics in the diagnosis and management of skin and soft-tissue infections. Int J Antimicrob Agents. 2016; 48:19-26.

13. Chan T, Yaghoubian A, Rosing D, Kaji A, de Virgilio C. Low sensitivity of physical examination findings in necrotizing soft tissue infection is improved with laboratory values: a prospective study. Am J Surg. 2008; 196: 926-930.

14. Hadeed GJ, Smith J, O'Keeffe T, Kulvatunyou N, Wynne JL, Joseph B, et al. Early surgical intervention and its impact on patients presenting with necrotizing soft tissue infections: A single academic center experience. J Emerg Trauma Shock. 2016; 9: 22-27.

15. Devaney B, Frawley G, Frawley L, Pilcher DV. Necrotising soft tissue infections: the effect of hyperbaric oxygen on mortality. Anaesth Intensive Care. 2015; 43: 685-692.

16. Marinis A, Voultsos M, Grivas P, Dikeakos P, Liarmakopoulos E, Paschalidis N, et al. Vacuumassisted therapy accelerates wound healing in necrotizing soft tissue infections: our experience in two intravenous drug abuse patients. Infez Med. $2013 ; 21: 305-311$.

17. Dryden MS. Reactive Oxygen therapy: a novel therapy in soft tissue infection. Current Opinion in Infectious Disease 2017; 30:143-149.

18. Lamagni TL, Neal S, Keshishian C, Alhaddad N, George R, Duckworth G, et al. Severe Streptococcus pyogenes infections, United Kingdom, 2003-2004. Emerg Infect Dis 2008; 14: 202- 
19. Turner C, Dryden M, Holden M, Davies F, Lawrenson R, Farzaneh L, et al. Lethal Streptococcus pyogenes post-partum sepsis: Molecular analysis of an outbreak. J Clin Microbiol. 2013; 51: 2089-2095. doi: 10.1128/JCM.00679-13

20. Nizet V. Understanding how leading bacterial pathogens subvert innate immunity to reveal novel therapeutic targets. J Allergy Clin Immunol 2007; 120: 13-22

21. Steer JA, Lamagni T, Healy B, Morgan M, Dryden M, Rao B, et al. Guidelines for prevention and control of group A streptococcal infection in acute healthcare and maternity settings in the UK. J Infect. $2012 ; 64: 1-18$.

22. Sultan HY, Boyle AA, Sheppard N. Necrotising fasciitis. BMJ 2012: 345 e4274

23. Chen IC, Li WC, Hong YC, Shie SS, Fann WC, Hsiao CT. The microbiological profile and presence of bloodstream infection influence mortality rates in necrotizing fasciitis. Crit Care. 2011 21;15:R152.

24. Lee CC, Chi CH, Lee NY, Lee HC, Chen CL, Chen PL, et al. Necrotizing fasciitis in patients with liver cirrhosis: predominance of monomicrobial Gram-negative bacillary infections. Diagn Microbiol Infect Dis. 2008; 62: 219-25.

25. Kuo YL, Shieh SJ, Chiu HY, Lee JW. Necrotizing fasciitis caused by Vibrio vulnificus: epidemiology, clinical findings, treatment and prevention. Eur J Clin Microbiol Infect Dis. 2007; 26: 785-92.

26. Lee YC, Hor LI, Chiu HY, Lee JW, Shieh SJ. Prognostic factor of mortality and its clinical implications in patients with necrotizing fasciitis caused by Vibrio vulnificus. Eur J Clin Microbiol Infect Dis. 2014; 33: 1011-1018.

27. Tsai YH, Wen-Wei Hsu R, Huang KC, Huang TJ. Comparison of necrotizing fasciitis and sepsis caused by Vibrio vulnificus and Staphylococcus aureus. J Bone Joint Surg Am. 2011;9 3: 274284.

28. Tsai YH, Hsu RW, Huang KC, Huang TJ. Laboratory indicators for early detection and surgical treatment of vibrio necrotizing fasciitis. Clin Orthop Relat Res. 2010; 468: 2230-2237. 
29. Chen SC, Lee YT, Tsai SJ, Chan KS, Chao WN, Wang PH, et al. Antibiotic therapy for necrotizing fasciitis caused by Vibrio vulnificus: retrospective analysis of an 8 year period. $\mathrm{J}$ Antimicrob Chemother. 2012; 67: 488-493.

30. Chao WN, Tsai CF, Chang HR, Chan KS, Su CH, Lee YT, et al. Impact of timing of surgery on outcome of Vibrio vulnificus-related necrotizing fasciitis. Am J Surg. 2013; 206: 32-39.

31. Hong GL, Dai XQ, Lu CJ, Liu JM, Zhao GJ, Wu B, et al. Temporizing surgical management improves outcome in patients with Vibrio necrotizing fasciitis complicated with septic shock on admission. Burns. 2014; 40: 446-454.

32. Shaked H, Samra Z, Paul M, Madar-Shapiro L, Cohen J, Pitlik S, et al. Unusual "flesh-eating" strains of Escherichia coli. J Clin Microbiol. 2012; 50: 4008-4011.

33. Kelesidis T, Tsiodras S. Postirradiation. Klebsiella pneumoniae-associated necrotizing fasciitis in the western hemisphere: a rare but life-threatening clinical entity. Am J Med Sci. 2009; 338: 217 224.

34. Reisman JS, Weinberg A, Ponte C, Kradin R. Monomicrobial necrotizing fasciitis: a case of infection by two strains and a review of 37 cases in the literature. Scand J Infect Dis. 2012;44:21621.

35. Khawcharoenporn T, Apisarnthanarak/A, Kiratisin P, Mundy LM. Salmonella group C necrotizing fasciitis: a case report and review of the literature. Diagn Microbiol Infect Dis. 2006; 54: 319-322.

36. Spadaro S, Berselli A, Marangoni E, Romanello A, Colamussi MV, Ragazzi R,et al. Aeromonas sobria necrotizing fassciitis and sepsis in an immunocompromised patient: a case report and review of the literature. J Med Case Rep. 2014 ; 22:315. doi: 10.1186/1752-1947-8-315.

37. Tena D, Arjas M, Alvarez BT, Mauleón C, Jiménez MP, Bisquert J. Fulminant necrotizing fasciitis due to Vibrio parahaemolyticus. J Med Microbiol. 2010;59 (Pt 2): 235-238.

38. Gillet Y, Dumitrescu O, Tristan A, Dauwalder O, Javouhey E, Floret D, et al. Pragmatic management of Panton-Valentine leukocidin-associated staphylococcal diseases. Int J Antimicrobial Agents 2011; $38: 457-464$. 
39. Gillet $Y$, Issartel B, Vanhems P, Fournet JC, Lina G, Bes M, et al. Association between staphylococcus aureus strains carrying gene for panton-valentine leukocidin and highly lethal necrotising pneumonia in young immunocompetent patients. Lancet 2002; 359: 753-759.

40. Rose HR, Holzman RS, Altman DR, Smyth DS, Wasserman GA, Kafer JM, et al. Cytotoxic virulence predicts mortality in nosocomial pneumonia due to methicillin-resistant staphylococcus aureus. J Infect Dis. 2015; 211:1862-1874.

41. Wardenburg JB, Palazzolo-Ballance AM, Otto M, Schneewind O, DeLeo FR. Panton-valentine leukocidin is not a virulence determinant in murine models of community-associated methicillinresistant staphylococcus aureus disease. J Infect Dis. 2008;198:1166-1170.

42. Stevens DL, Bisno AL, Chambers HF, Dellinger EP, Goldstein EJC, Gorbach SL, et al. Practice guidelines for the diagnosis and management of skin and soft tissue infections: 2014 update by the Infectious Diseases Society of America. Clin Infect Dis, 2014; 59:147-159.

43. Le VTM, Le HN, Pinheiro MG, Hahn KJ, Dinh ML, Larson KB, et al. Effects of tedizolid phosphate on survival outcomes and suppression of production of staphylococcal toxins in a rabbit model of methicillin-resistant staphylococcus aureus necrotizing pneumonia. Antimicrob Agents Chemother. 2017;61; 61(4): e02734-16.

44. Saeed K, Gould I, Esposito S, Ahmad-Saeed N, Ahmad S, Alp E, et al. Panton-Valentine Leucocidin (PVL) Staphylococcus aureus a position statement from the International Society of Chemotherapy. IJAA 2018: 51: 16-25.

45. Brindle R, Williams M, Davies P, Harris T, Jarman H, Hay A, et al. Adjunctive clindamycin for cellulitis: a clinidal trial comparing flucloxacillin with or without clindamycin for the treatment of limb cellulitis. BMJ Open 2017;7: e013260. doi:10.1136/ bmjopen-2016-013260

46. Petrikkos G, Skiada A, Lortholary O, Roilides E, Walsh TJ, Kontoyiannis DP. Epidemiology and Clinical Manifestations of Mucormycosis. Clin Infect Dis 2012; 54(Suppl 1): S23-S34.

47. Vitrat-Hincky V, Lebeau B, Bozonnet E, Falcon D, Pradel P, Faure O, et al. Severe filamentous fungal infections after widespread tissue damage due to traumatic injury: six cases and review of the literature. Scandinavian Journal of Infectious Diseases 2009;41:491-500 
48. Jain D, Kumar Y, Vasishta RK, Rajesh L, Pattari SK, Chakrabarti A. Zygomycotic necrotizing fasciitis in immunocompetent patients: a series of 18 cases. Mod Pathol 2006;19:1221-1226

49. Fanfair RN, Benedict K, Bos J, Bennett SD, Lo YC, Adebanjo T et al. Necrotizing cutaneous mucormycosis after a tornado in Joplin, Missouri in 2011. N Engl J Med 2012; 367; 2214-25.

50. Ho SWL, Ang CL, Ding CSL, Barkham T, Teoh LC. Necrotizing fasciitis caused by Cryptococcus gattii. Am J Orthop. 2015;44:E517-E522

51. Prasanna Kumar S, Ravikumar A, Somu L. Fungal necrotizing fasciitis in 3 patients with uncontrolled diabetes. Ear Nose Throat J. 2014; 93: E18-21.

52. Chander J, Stchigel AM, Alastruey-Izquierdo A, Jayant M, Bala K, Rani H, et al. Fungal necrotizing fasciitis, an emerging infectious disease caused by Apophysomyces (Mucorales). Rev Iberoam Micol. 2015; 32: 93-98

53. Neblett Fanfair R, Benedict K, Bos J, Bennett S, Lo Y, Adebanjo T, et al. Necrotizing cutaneous mucormycosis after a tornado in Joplin, Missouri, in 2011. N Engl J Med 2012; 367: 2214-25.

54. Kordy FN, Al-Mohsen IZ, Hashem F, Almodovar E, AlHajjar S, Walsh TJ. Successful treatment of a child with post traumatic necrotizing fasciitis caused by Apophysomyces elegans: case report and review of literature. Pediatr Infect Dis J. 2004; 23: 877-879.

55. Ruiz CE, Arango M, Correa AL, Lopez LS, Restrepo A. Necrotizing fasciitis in an immunocompetent patient caused by Apophysomyces elegans. Biomedica 2004; 24:239-251.

56. Spellberg B, Ibrahim A, Roilides E, Lewis R, Lortholary O, Petrikkos G, et al. Combination therapy for mucormycosis: why, what, and how? Clin Infect Dis 2012; 54(Suppl 1): S73-8.

57. Martinelli G, Alessandrino EP, Bernasconi P, Caldera D, Colombo A, Malcovati L, et al. Fournier's gangrene: a clinical presentation of necrotizing fasciitis after bone marrow transplantation. Bone Marrow Transplantation, 1998; 22: 1023-1026.

58. Mills MK, Faraklas I, Davis C, Stoddard GJ, Saffle J. Outcomes from treatment of necrotizing soft-tissue infections: results from the National Surgical Quality Improvement Program database. Am J Surg. 2010 ;200:790-6; discussion 796-7. doi: 10.1016/j.amjsurg.2010.06.008. 
59. Keung EZ, Liu X, Nuzhad A, Adams C, Ashley SW, Askari R. Immunocompromised Status in patients with necrotizing soft-tissue infection. JAMA Surg. 2013;148:419-426. doi:10.1001/jamasurg.2013.173

60. Vaiman M, Lazarovitch T, Heller L \& Lotan G. Ecthyma gangrenosum and ecthyma-like lesions: review article Eur J Clin Microbiol Infect Dis 2015; 34:633-639.

61. Nakanishi K and Kinjo M. Mimicker of necrotising fasciitis with systemic inflammatory response syndrome: recurrent necrotising Sweet's syndrome associated with chronic myelogenous leukaemia. BMJ Case Rep 2016. doi: 10.1136/bcr-2016-214461.

62. Levine DP, Crane LR, Zervos MJ. Bacteremia in narcotic addicts at the Detroit Medical Center. I. Microbiology, epidemiology, risk factors, and empiric therapy. Rev Infect Dis, 1986. 8: 364-73.

63. Dahlman D, Håkansson A, Björkman P, Blomé MA, Kral AH. Correlátes of Skin and Soft Tissue Infections in Injection Drug Users in a Syringe-Exchange Program in Malmo, Sweden. Subst Use Misuse, 2015. 50: 1529-35.

64. Binswanger IA,, Takahashi TA, Bradley K, Dellit TH, Benton KL, Merrill JO. Drug users seeking emergency care for soft tissue infection at high risk for subsequent hospitalization and death. J Stud Alcohol Drugs, 2008. 69: 924-32.

65. Murphy EL, DeVita D, Liu H, Vittinghoff E, Leung P, Ciccarone DH, et al. Risk factors for skin and soft-tissue abscesses among injection drug users: a case-control study. Clin Infect Dis. 2001;33 :35-40.

66. Ebright JR, Pieper B. Skin and soft tissue infections in injection drug users. Infect Dis Clin North Am. 2002;16:697-712

67. Dancer SJ,McNair D, Finn P, Kolsto A. Bacillus cereus cellulitis from contaminated heroin. J Med Microbiol 2002; 51, 278-281.

68. Dunbar N M \& Harruff R C . Necrotizing fasciitis: manifestations, microbiology and connection with black tar heroin. J Forensic Sci 2007;52: 920-923.

69. Passaro D J, Werner S B, McGee J, Mac Kenzie W R \& Vugia D J . Wound botulism associated with black tar heroin among injecting drug users. JAMA 1998; 279: 859-863. 
70. Pascual FB, McGinley EL, Zanardi LR, Cortese MM \& Murphy TV. Tetanus surveillance United States, 1998-2000. MMWR Surveill Summ 2003; 52: 1-8.

71. Totapally BR. Epidemiology and outcomes of hospitalized children with necrotizing soft-tissue infections. Pediatr Infect Dis J. 2017;36:641-644. doi: 10.1097/INF.0000000000001498

72. Endorf FW, Garrison MM, Klein MB, Richardson A, Rivara FP. Characteristics, therapies, and outcome of children with necrotizing soft tissue infections. Pediatr Infect Dis J. 2012; 31: 221-3. doi: 10.1097/INF.0b013e3182456f02.

73. Zundel S, Lemaréchal A, Kaiser P, Szavay P. Diagnosis and treatment of pediatric necrotizing fasciitis: a systematic review of the literature. Eur J Pediatr Surg. 2017 ; 27: 127-137. doi: $10.1055 / \mathrm{s}-0036-1584531$.

74. Crum NF. Bacterial pyomyositis in the United States. Am J Med 2004; 117: 420.

75. Small LN, Ross JJ. Tropical and temperate pyomyositis. Infect Dis Clin North Am 2005;19:981.

76. Comegna L, Guidone PI, Prezioso G, Franchini S, Petrosino MI, Di Filippo P, et al. Pyomyositis is not only a tropical pathology: a case series. J Med Case Rep. 2016;10:372.

77. Sissolak, D. and W.R. Weir, Tropical pyomyositis. J Infect, 1994; 29: 121-7.

78. Rayes AA, Nobre V, Teixeira DM, Serufo JC, Filho GB, Antunes CM, et al. Tropical pyomyositis and human toxocariasis: a clinical and experimental study. Am J Med, 2000: 109: 422-5.

79. Struk DW, Munk PL, Lee MJ, Ho SG, Worsley DF. Imaging of soft tissue infections. Radiol Clin North Am. 2001;39:277-303.

80. Theodorou SJ, Theodorou DJ, Resnick D. MR imaging findings of pyogenic bacterial myositis (pyomyositis) in patients with local muscle trauma: illustrative cases. Emerg Radiol. 2007;14:8996.

81. Stevens DL, Maier KA, Laine BM, Mitten JE. Comparison of clindamycin, rifampin, tetracycline, metronidazole, and penicillin for efficacy in prevention of experimental gas gangrene due to Clostridium perfringens. J Infect Dis. 1987 ; 155:220-8.

82. Takazawa K, Otsuka H, Nakagawa Y, Inokuchi S. Clinical Features of Non-clostridial Gas Gangrene and Risk Factors for In-hospital Mortality. Tokai J Exp Clin Med. 2015 ; 40 :124-9. 
83. Stevens DL, Bisno AL, Chambers HF, Everett ED, Dellinger P, Goldstein EJ. Practice guidelines for the diagnosis and management of skin and soft-tissue infections. Clin Infect Dis. 2005 ; 41:1373-406.

84. Department of Health UK. Clinical guidelines for immunoglobulin use, 2008. Available via https://www.gov.uk/government/publications/clinical-guidelines-for-immunoglobulin-usesecond-edition-update last accessed 17 November 2017.

85. Takei S, Arora YK, Walker SM. Intravenous immunoglobulin contains specific antibodies inhibitory to activation of T cells by staphylococcal toxin superantigens. J. Clin. Investig. 1993;91:602-607

86. Norrby-Teglund A, Kaul R, Low DE, McGeer A, Newton DW, Andersson J. Plasma from patients with severe invasive Group A streptococcal infections treated with normal polyspecific IgG inhibits streptococcal superantigen-induced $\mathrm{T}$ cell prolifération and cytokine production. J. Immunol. 1996;156:3057-3064

87. Basma H, Norrby-Teglund A, McGeer A, Low DE, El-Ahmedy O, Dale JB, et al. Opsonic antibodies to the surface M protein of group A streptococci in pooled normal immunoglobulins (IVIG): potential impact on the clinical efficacy of IVIG therapy for severe invasive group A streptococcal infections. Infect Immun 1998;66:2279-83.

88. Sriskandan S, Ferguson M, Elliot V, Faulkner L, Cohen J.. Human intravenous immunoglobulin for experimental streptococcal toxic shock: bacterial clearance and modulation of inflammation. $\mathrm{J}$ Antimicrob Chemother 2006;58:117-24.

89. Koch C, Hecker A, Grau V, Padberg W, Wolff M \& Hendrich M. Intravenous immunoglobulin in necrotizing/fasciitis - A case report and review of recent literature Ann Med Surg 2015 ; 4: 260263.

90. Raithatha AH \& Bruden DC. Use of intravenous immunoglobulin therapy in the treatment of septic shock, in particular severe invasive group A streptococcal disease, Indian J Crit Care Med 2012; $16: 37-40$ 
91. Cawley M, Briggs M, Haith LJ, Reilly KJ, Guilday RE, Braxton GR, et al. Intravenous immunoglobulin as adjunctive treatment for streptococcal toxic shock syndrome associated with necrotizing fasciitis: case report and review. Pharmacotherapy 1999; 19:1094-8.

92. Darenberg J, Ihendyane N, Sjölin J, Aufwerber E, Haidl S, Follin P, et al. Intravenous immunoglobulin G therapy in streptococcal toxic shock syndrome: A European randomised, double-blind, placebo-controlled trial. Clin Infect Dis. 2003;37:333-40

93. Kaul R, McGeer A, Norrby-Teglund A, Kotb M, Schwartz B, O'Rourke K, et al. Intravenous immunoglobulin therapy for streptococcal toxic shock syndrome - a comparative observational study. Canadian Streptococcal Study Group. Clin Infect Dis 1999; 28: 800-807.

94. Linner A, Darenberg J, Sjolin J, Henriques-Normark B, \& Norrby-Teglund A. Clinical Efficacy of Polyspecific Intravenous Immunoglobulin Therapy in Patients With Streptococcal Toxic Shock Syndrome: A Comparative Observational Study Clin Infect Dis 2014; 59 : 851-857.

95. Shah SS, Hall M, Srivstava R, Subramony A \& Levin JE. Intravenous immunoglobulin in children with streptococcal toxic shock syndrome, Clin Infect Dis 2009;49:1369-76 
Figure 1: Early recognition of necrotising soft tissue infection aid memoir

$\mathbf{N}_{\text {ecrotic (or cellulitis area) }}$

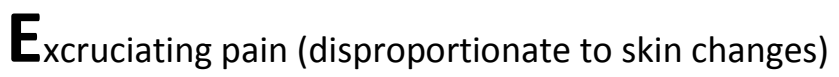

Crepitus (may not be always present) $_{\text {. }}$

$F_{\text {ever (with or without raised inflammatory markers) }}$

Ascending (demarcate the area with date/time)

Swelling

Contact surgeons (urgently if any clinical suspicion, even if the above features not present)

Figure 2a. Rapid changes in the abdominal wall with blistering and possible necrosis was noted

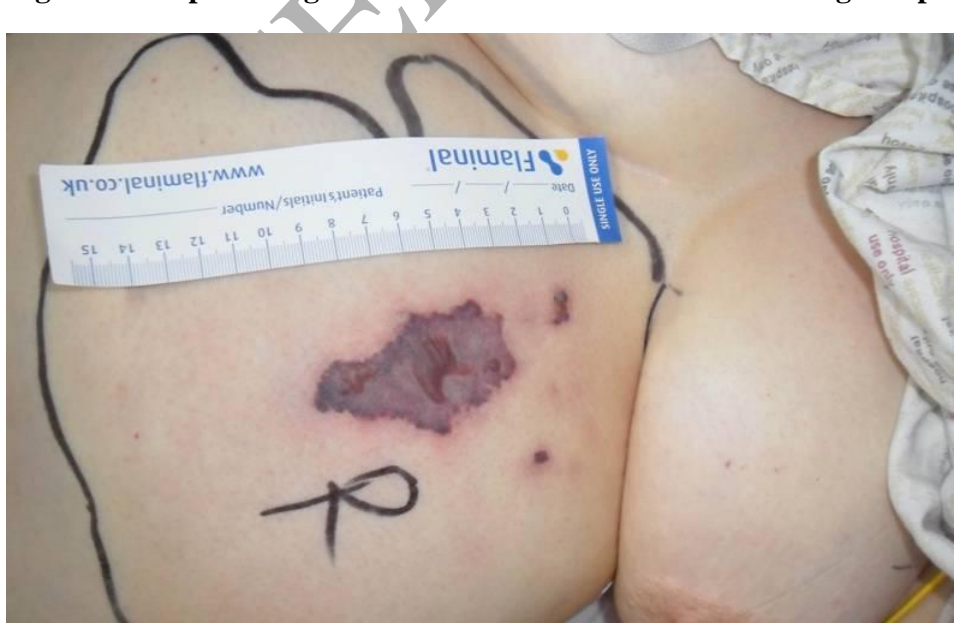

The patient had a fall at home and was admitted to the emergency department (ED) with a bruised chest wall and possible rib fracture; she was discharged with analgesia. Four days later she was readmitted in a confused state and complaining of a 
headache. She had no significant past medical history apart from penicillin allergy and a significant alcohol intake of $100 \mathrm{~g}$ (10 standard drinks)/ week. On examination there was extensive left chest and abdominal wall bruising, in keeping with the previous fall and local trauma. Diffuse erythema was also noted over the anterior abdominal wall and there was a slight break, but no discharge, in the skin at the site of presumed injury associated with the fall. A diagnosis of delayed splenic rupture was suggested and she had an abdominal ultrasound, which showed no abdominal free fluid or gas and a possible small haematoma in the abdominal wall. A surgical consultation recorded that there were no surgical concerns.

Investigations were as follows: Hb $109 \mathrm{gm} / \mathrm{L}$, WBC 11.9, platelets 120, CRP 87 with normal renal and liver function. An infectious diseases opinion was sought. The mild erythema was felt to be early cellulitis and empirical treatment with IV clindamycin $600 \mathrm{mg}$ qds was commenced.

Two hours later the patient became more confused, acidotic and the CRP increased to 240 and WBC to 18.9. She was transferred to intensive care (ICU) where rapid changes in the abdominal wall with blistering and possible necrosis was noted as demonstrated in the picture.

Figure 2b. After debridement.

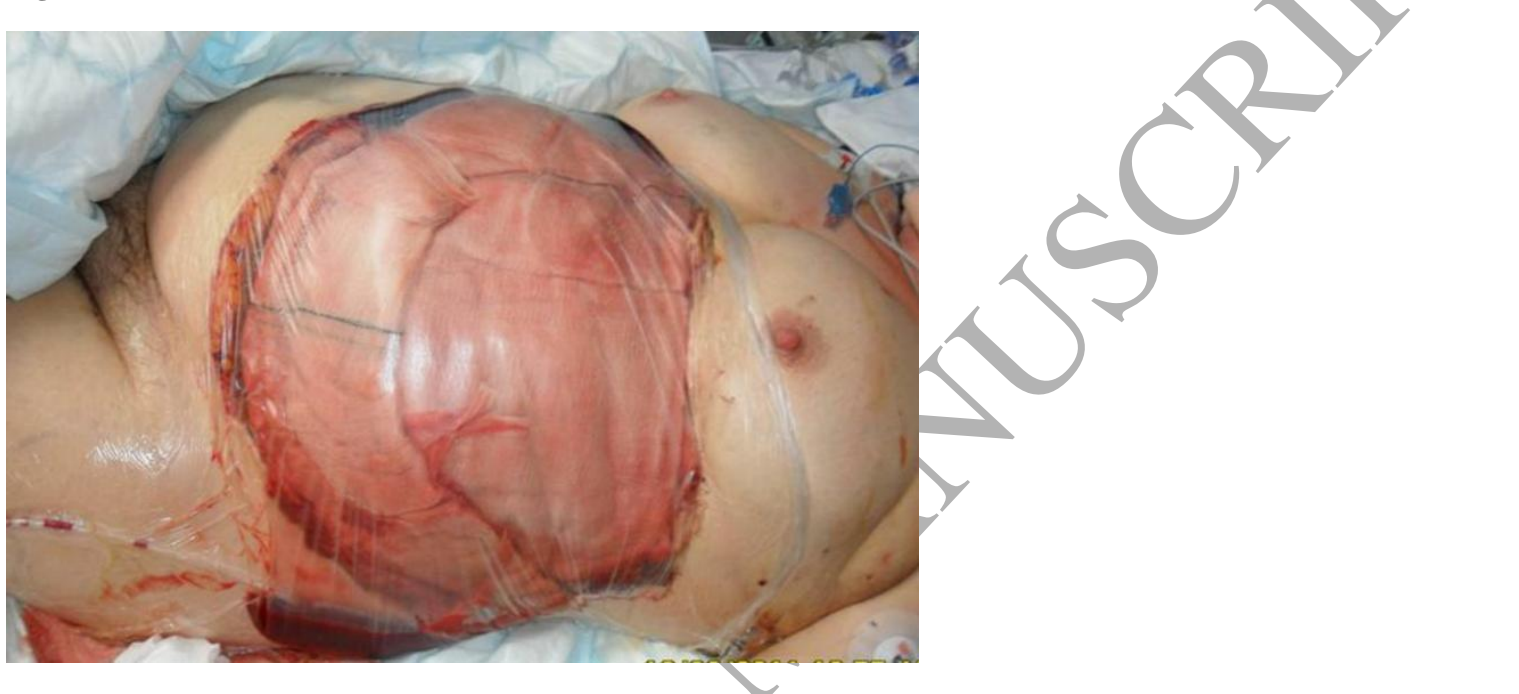

A further ultrasound showed an abdominal wall fluid collection and an urgent CT scan showed

extensive subcutaneous oedema at the left flank overlying the left ribs. Her blood pressure was 80/45 $\mathrm{mmHg}$ and she required cardiovascular support with dobutamine and noradrenaline. She underwent surgical debridement as demonstrated. A Gram stain of the debrided tissue showed short chains of Gram positive cocci, and subsequent culture grew GAS. She was treated empirically with meropenem and linezolid and received two doses of IVIG at doses of $2 \mathrm{gm} / \mathrm{kg}$. The patient had three further surgical debridement and remained in the ICU for two months. 
Table 1: Antibiotic treatment of necrotising fasciitis

\begin{tabular}{|l|l|}
\hline \multicolumn{1}{|c|}{ Type of necrotising fasciitis } & \multicolumn{1}{c|}{ Antibiotic treatment } \\
\hline $\begin{array}{l}\text { Unknown etiology (empirical*) or } \\
\text { Polymicrobial (aerobic and anaerobic } \\
\text { pathogens) }\end{array}$ & $\begin{array}{l}\text { Beta lactams (Piperacillin/Tazobactam or Cabapenem or Cephalosporins) plus } \\
\text { Clindamycin } \\
\text { In true Beta lactam allergic patients substitute the beta lactam with a fluoroquinolone }\end{array}$ \\
\hline $\begin{array}{l}\text { Suspicion or confirmed MRSA } \\
\begin{array}{l}\text { Targeted treatment for streptococcal or } \\
\text { clostridial infections }\end{array}\end{array}$ & $\begin{array}{l}\text { Add: Vancomycin or Daptomicin or Linezolid or other new alternatives e.g. Tedizolid, } \\
\text { Dalbavancin, Ceftaroline, Tigecycline }\end{array}$ \\
\hline
\end{tabular}

*NF is a surgical emergency and urgent referral to surgeons is a priority.

Abscesses need to be drained (in IVDUs)

Imaging is important, but normal imaging does not exclude the diagnosis of NF

Always follow local epidemiology and guidance. The optimal duration of antibiotic treatment has not been defined.

Antibiotics should be continued until surgical treatment is completed (no additional debridement is needed), the patient has improved clinically and fever has resolved for 48-72 hours.

Table2: Summary salient clinical data from the largest reported case series and literature reviews on other Gram negative bacterial NF.

\begin{tabular}{|l|l|l|l|l|l|l|l|}
\hline Pathogen & $\begin{array}{l}\text { Number of } \\
\text { cases }\end{array}$ & Age (years) & Male & $\begin{array}{l}\text { Predisposing } \\
\text { conditions }\end{array}$ & $\begin{array}{l}\text { Surgery } \\
\text { performed }\end{array}$ & $\begin{array}{l}\text { No of } \\
\text { Death } \\
(\%)\end{array}$ & $\begin{array}{l}\text { Refernce } \\
\text { Escherichia coli }\end{array}$ \\
\hline Klebsiella spp. & 17 & $52-91$ & $5(71 \%)$ & $\begin{array}{l}\text { Cancer 3 (43\%), } \\
\text { liver disorder } 1 \\
(14 \%)\end{array}$ & $2(29 \%)$ & $7(100 \%)$ & 32 \\
\hline Pseudomonas spp. & 37 & $1-76$ & $13(76 \%)$ & $\begin{array}{l}\text { Diabetes 12 } \\
(71 \%), \text { liver } \\
\text { disorder 4 (24\%), } \\
\text { cancer 2(12\%) }\end{array}$ & $13(76 \%)$ & $5(29 \%)$ & 33 \\
\hline Salmonella spp. & 6 & 2 months-85 & $15(41 \%)$ & $\begin{array}{l}\text { Cancer 20 } \\
(54 \%), \text { diabetes 1 } \\
(3 \%)\end{array}$ & $16(43 \%)$ & $9(24 \%)$ & 34 \\
\hline
\end{tabular}




\begin{tabular}{|l|l|l|l|l|l|l|l|}
\hline Aeromonas spp. & 13 & $41-81$ & $11(85 \%)$ & $\begin{array}{l}\text { Cancer 5 (38\%), } \\
\text { diabetes 3 (23\%), } \\
\text { liver disorder 3 } \\
(23 \%)\end{array}$ & $9(69 \%)$ & 36 \\
\hline $\begin{array}{l}\text { Vibrio } \\
\text { parahaemolyticus }\end{array}$ & 8 & $40-92$ & $7(88 \%)$ & $\begin{array}{l}\text { Diabetes 4 } \\
(50 \%), \text { liver } \\
\text { disorder 3 (38\%) }\end{array}$ & $6(75 \%)$ & $3(38 \%)$ & 37 \\
\hline
\end{tabular}

Table 3: Clinical stages of pyomyositis and management summary

\begin{tabular}{|l|l|l}
\hline Stage & Description & Management summary \\
\hline $\begin{array}{l}\text { Stage 1 or } \\
\text { invasive stage }\end{array}$ & $\begin{array}{l}\text { Around 2\% of patients present in this stage. This stage lasts from 10 } \\
\text { to 21 days. There is an insidious onset of dull, cramping pain, low- } \\
\text { grade fever, muscle ache, general malaise and anorexia. There is } \\
\text { localized oedema, sometimes described as indurated or woody, with } \\
\text { little or no tenderness. There is no abscess, and examination of } \\
\text { aspiration specimens is unrevealing. }\end{array}$ & $\begin{array}{l}\text { Antibiotics tend to be sufficie } \\
\text { active against S. aureus (incll } \\
\text { beta-haemolytic streptococci. } \\
\text { use, are vancomycin, daptom, } \\
\text { Due to its potency to inhibit t } \\
\text { may be added to vancomycin } \\
\text { must also cover Gram negatis } \\
\text { immunocompromised hosts. } \\
\text { sulbactam, amoxicillin-clavul } \\
\text { tazobactam must be combiner } \\
\text { against MRSA. The recomm } \\
\text { 2-3 weeks. }\end{array}$ \\
\hline $\begin{array}{l}\text { Stage 2 or } \\
\text { purulent or } \\
\text { suppurative } \\
\text { stage }\end{array}$ & $\begin{array}{l}\text { About 90\% of patients present in this stage. Mean duration of } \\
\text { symptoms varies from 24 hours to 12 days. Fever and chills are } \\
\text { usually present. This stage is characterized by abscess formation. } \\
\text { Pathologic findings on biopsy show oedematous muscle fibers, } \\
\text { lymphocytic infiltration, and suppuration as the muscle belly is } \\
\text { replaced by pus. The involved muscle is usually tender and the } \\
\text { overlying skin may be normal or mildly eruptive. }\end{array}$ & $\begin{array}{l}\text { In addition to antibiotics as al } \\
\text { percutaneous drainage should } \\
\text { pyomyositis. Surgical interve } \\
\text { percutaneous drainage or mus }\end{array}$ \\
\hline $\begin{array}{l}\text { Stage } 3 \text { or } \\
\text { late stage }\end{array}$ & $\begin{array}{l}\text { High fever, severe pain, local signs of infection and systemic } \\
\text { manifestations of sepsis may be present. The final stage is } \\
\text { characterized by septicemia, metastatic abscesses, and multi-organ } \\
\text { dysfunction which is associated with high mortality. There is } \\
\text { exquisite tenderness of the involved area. }\end{array}$ & \begin{tabular}{l} 
\\
\hline
\end{tabular}
\end{tabular}

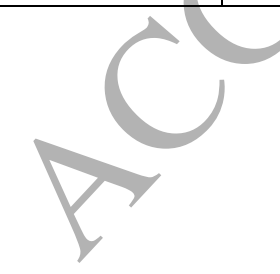

